\title{
Duplication of medial 15q confirmed by FISH
}

EDITOR - The proband was a male infant born to a 28 year old mother and 24 year old father. The parents were healthy and non-consanguineous. There was no significant family history. The pregnancy was complicated by intrauterine growth retardation. At term, birth weight was 2300 $\mathrm{g}$ and bilateral talipes were noted, as were a number of dysmorphic features. These included an enlarged anterior fontanelle with widely spaced sutures, downward slanting palpebral fissures, a flat occiput, a smooth philtrum, prominent nasal bridge, fleshy nasal tip, prominent forehead, and micrognathia (fig 1A). Deep creases were noted on both hands and feet, and the second, third, and fourth fingers of both hands were unusually long (fig $1 \mathrm{~B}$, C). The infant suffered from respiratory complications and failure to thrive. Further investigations showed hypothyroidism and a vascular ring (which was subsequently repaired). At 8 months old he had occasional feeding difficulties and moderate growth retardation.

Short term peripheral blood lymphocyte cultures were initiated and harvested by standard protocols. G banded analysis was carried out using trypsin digestion followed by Leishman staining. All metaphases examined showed a male karyotype with an interstitial duplication of the long arm of chromosome 15 between bands q21 and q24 (fig 2). Parental karyotypes were normal. Fluorescence in situ hybridisation (FISH) was undertaken using a TRITC labelled whole chromosome 15 specific paint (wcp15) by the method provided by the supplier (Oncor Ltd, Banbury, UK). This confirmed the duplicated material to be of

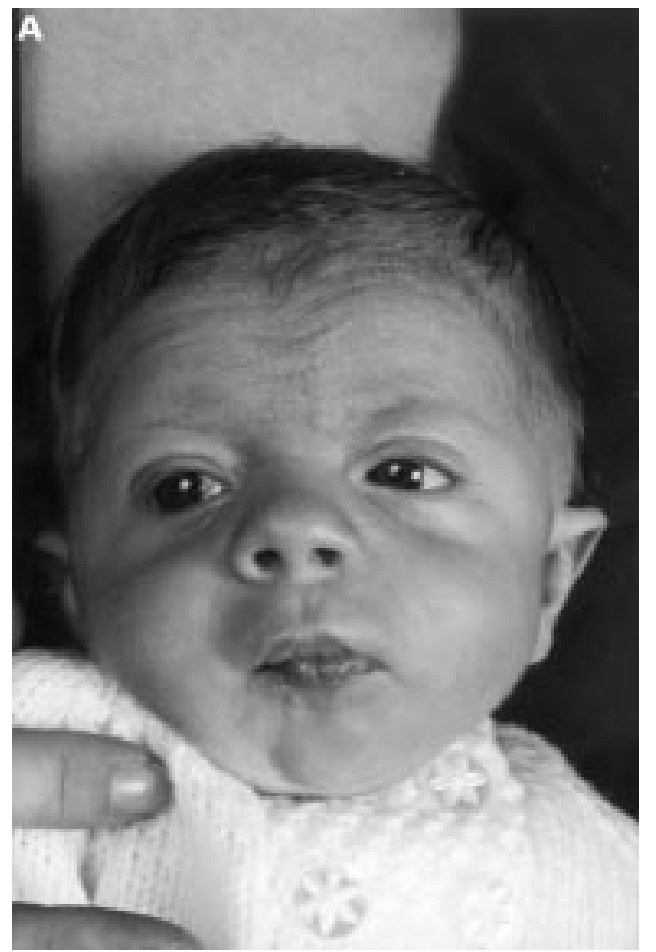

chromosome 15 origin (fig 3, above). Subsequently, FISH was undertaken using four band specific YAC probes, 900D08, 958H02, 812E02, and 928D07 (supplied by the YAC Screening Centre, Milan; http://www.spr.it/iger/ home.html), which map to the regions 15q21-q22, 15q23, 15q24, and 15q24-q25, respectively. Fig 3 (below) shows the FISH results using the probes 900D08 and 812E02 only. The results confirmed the cytogenetic findings; therefore, the proband's karyotype was 46,XY,dir $\operatorname{dup}(15)(\mathrm{q} 21 \mathrm{q} 24)$ de novo.ish $\operatorname{dup}(15)($ wcp $15+$, 900D08++,958H02++,812E02++,928D07++).

A review of published reports (table 1 ) showed 18 families (29 subjects) with partial trisomy for the region of $15 \mathrm{q}$ duplicated in our case. ${ }^{1-16}$ The majority of cases (15/18) had breakpoints within $15 \mathrm{q} 21 \rightarrow \mathrm{q} 22$, while one had a breakpoint at $15 \mathrm{q} 14$, one at $15 \mathrm{q} 15$, and one at $15 \mathrm{q} 23$.

Almost all cases (16/18) were the result of a parental rearrangement and, therefore, also involved partial monosomy for another chromosome. However, most of these had distal breakpoints and the monosomic material most likely contributed minimally to the phenotype. Only two cases involved a tandem duplication ${ }^{415}$ and one of these was in mosaic form. ${ }^{4}$ The other case was interstitial involving the region $15 \mathrm{q} 14 \rightarrow \mathrm{q} 21.1$, therefore overlapping only minimally with our case. ${ }^{15}$

Features common to the majority of cases with distal 15q trisomy included growth and mental retardation, hypotonia, and distinctive facial features including facial asymmetry, puffy cheeks, a short neck, downward slanting, narrow, palpebral fissures, ptosis, prominent nose with a broad nasal bridge, an abnormal philtrum, downturned mouth, high arched palate, midline crease in the lower lip, micrognathia, and microcephaly. The presence of congenital heart disease, skeletal abnormalities, respiratory distress/
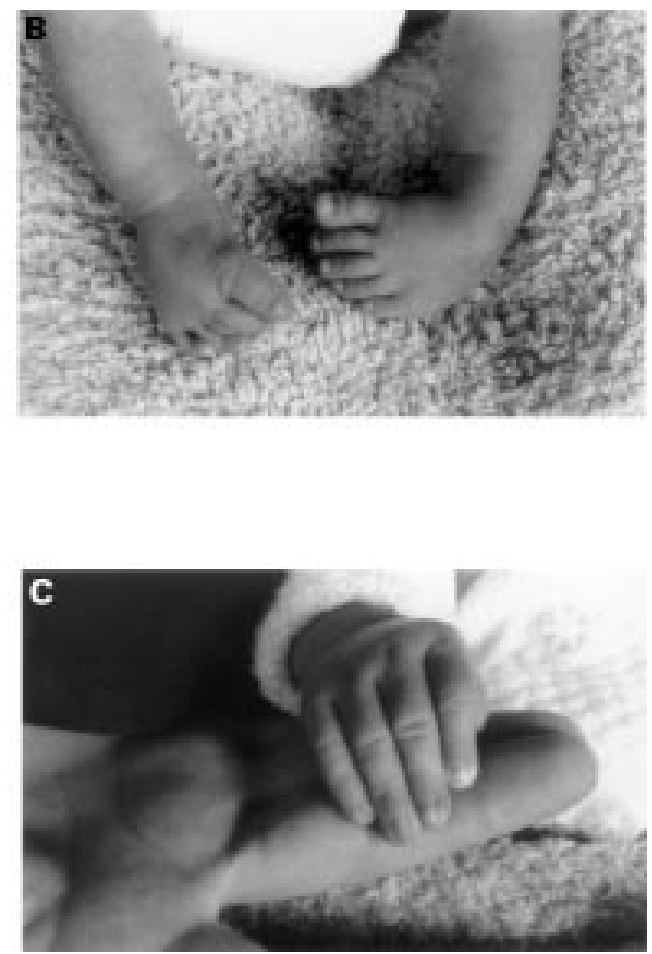

Figure 1 Clinical appearance of the proband showing (A) dysmorphic features, (B) bilateral talipes, and (C) long, tapering fingers. 


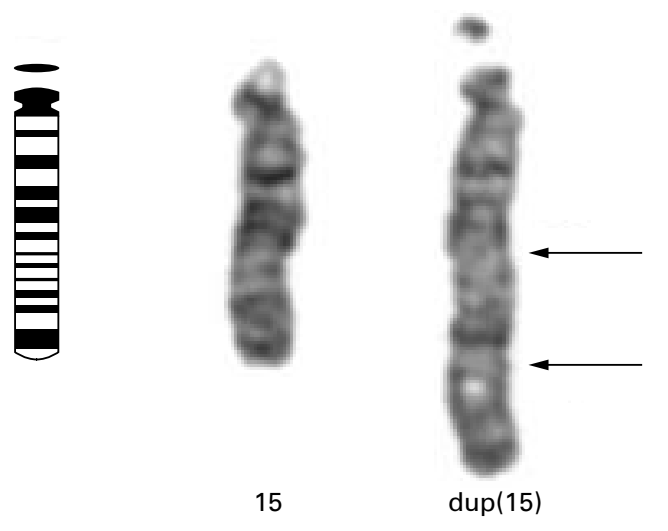

Figure 2 Partial G banded karyotype of the proband. Arrows indicate the breakpoints.
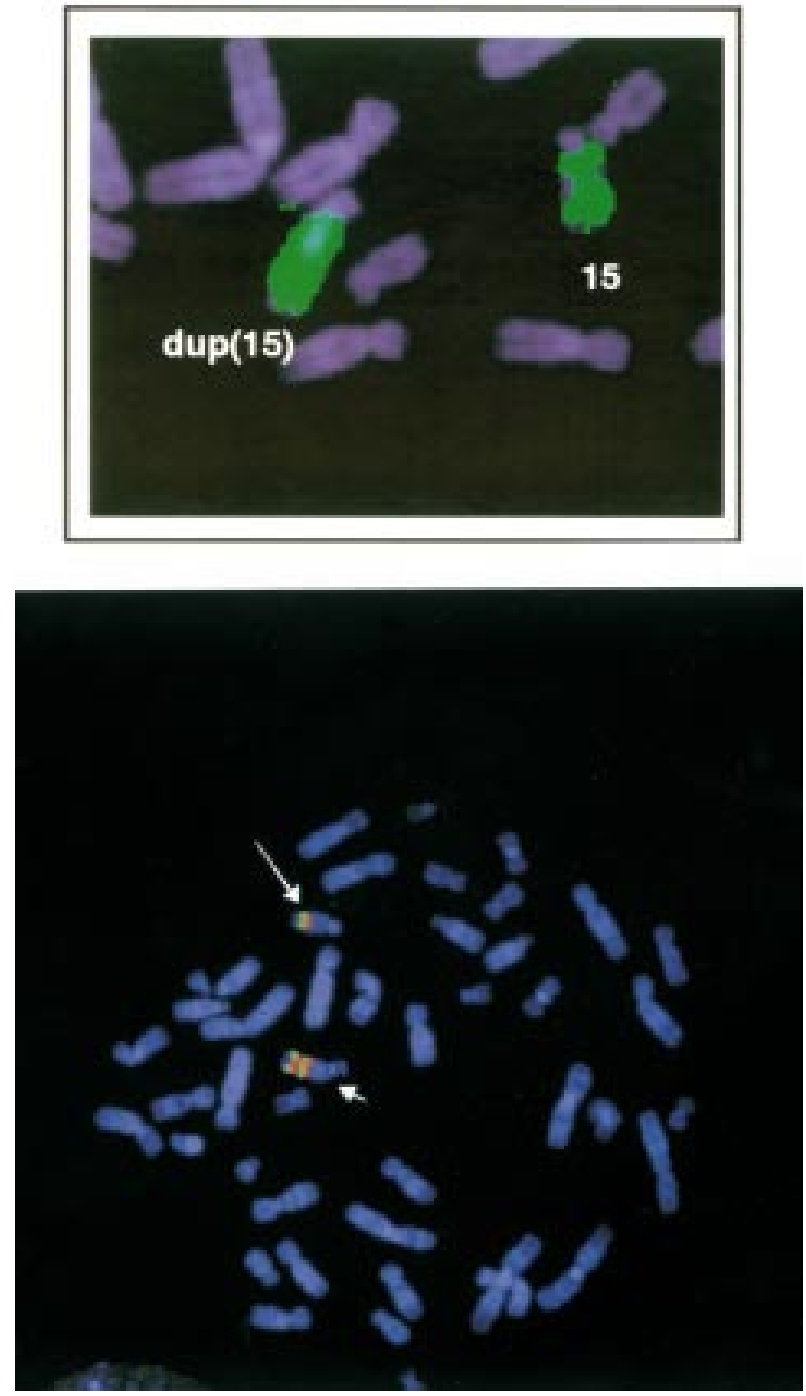

Figure 3 (Above) FISH with wcp15 indicating dup (15) paints entirely. (Below) FISH using the YAC probes $900 D O 8$ (red) and $812 E O 2$ (green) confirmed a direct duplication. (FISH using YACs $958 \mathrm{HO} 2$ and $928 D 07$ produced the same result.)

infection, and seizures varied among patients. Our case is, to our knowledge, the first de novo interstitial tandem
Table 1 Clinical features in reported cases of medial/distal 15q trisomy

\begin{tabular}{llll}
\hline Clinical features & $\begin{array}{l}\text { Present } \\
\text { case }\end{array}$ & $\begin{array}{l}\text { Previous } \\
\text { cases }\end{array}$ & $\begin{array}{l}\text { Previous } \\
\text { interstitial } \\
\text { duplication }\end{array}$ \\
\hline Mental deficiency & $?$ & $27 / 27$ & + \\
Hypotonia & - & $14 / 24$ & 0 \\
Hypertonia & - & $7 / 25$ & 0 \\
Seizures & - & $9 / 27$ & + \\
Growth delay & + & $14 / 25$ & + \\
Microcephaly & + & $15 / 29$ & + \\
Sloping forehead & + & $12 / 27$ & - \\
Facial asymmetry & - & $17 / 24$ & 0 \\
Downward slanting palpebral fissures & + & $19 / 26$ & - \\
Ptosis & - & $9 / 16$ & - \\
Prominent nose, broad nasal bridge & + & $26 / 27$ & + \\
Long, smooth, or well defined philtrum & + & $22 / 28$ & + \\
Downturned mouth & - & $18 / 21$ & 0 \\
High arched palate & - & $17 / 17$ & + \\
Midline crease lower lip & + & $12 / 14$ & 0 \\
Micrognathia & + & $25 / 28$ & + \\
Puffy cheeks & + & $14 / 20$ & 0 \\
Pectus excavatum & - & $15 / 21$ & 0 \\
Scoliosis & - & $12 / 18$ & + \\
Short neck & + & $17 / 25$ & + \\
Arachnodactyly & + & $9 / 12$ & + \\
Camptodactyly & - & $7 / 7$ & 0 \\
Cardiovascular defects & - & $19 / 29$ & - \\
& & &
\end{tabular}

- not present, + present, 0 not mentioned, ? unknown

duplication of only the medial region of $15 \mathrm{q}$. The abnormalities seen in this patient are consistent with previously reported cases of partial trisomy $15 \mathrm{q}$ and suggest a clinically recognisable phenotype.

C E BROWNE* E HATCHWELL† A PROTOPAPOS $\ddagger$ J RAMOS $†$

*Wessex Regional Genetics Laboratory, Salisbury District Hospital, Salisbury, Wiltshire SP2 8BF, UK

†Wessex Clinical Genetics Service, Princess Anne Hospital, Southampton, Hants SO16 5YA, UK

$\ddagger$ Department of Cardiothoracic Surgery, Southampton General Hospital, Southampton, Hants SO16 6YD, UK

Correspondence to: Dr Browne, wessex.genetics@dial.pipex.com

1 Vanallen MI, Siegel-Bartelt J, Feigenbaum A, Teshima IE. Craniosynostosis associated with partial duplication of $15 \mathrm{q}$ and deletion of 2q. Am F Med Genet 1992;43:688-92.

2 Pedersen C. Partial trisomy 15 as a result of an unbalanced 12/15 translocation in a patient with a cloverleaf skull anomaly. Clin Genet 1976;9:37880.

3 Tzancheva M, Krachounova M, Damjanova ZV. Two familial cases with trisomy $15 \mathrm{q}$ dist due to a $\operatorname{rcp}(5 ; 15)(\mathrm{p} 14 ; \mathrm{q} 21)$. Hum Genet $1981 ; 56: 275-7$.

4 Yip MY, Parsons A, Hulten M. A de novo tandem duplication 15(q21-qter) mosaic. Clin Genet 1982;22:1-6.

5 Lacro RV, Lyons Jones K, Mascarello JT, Jones OW, Wilson N, Jones MC Duplication of distal 15q: report of five new cases from two different transDuplication of distal 15q: report of five new cases from two different trans-

6 location kindreds. Am M .

6 Coco R, Penchaszadeh VB. Inherited partial duplication deficiency of chromosome 15(p12q22). F Genet Hum 1978;26:203-10.

Fujimoto A, Towner JW, Ebbin AJ, Kahlstrom EJ, Wilson MG. Inherited partial duplication of chromosome no 15. F Med Genet 1974;11:287-91.

8 Kristoffersson U, Bergwall B. Partial trisomy 15(q25qter) in two brothers. Heredity 1984;100:7-10.

9 Orye E, Laureys G, Verhaaren H. Mosaic and non-mosaic trisomy $15 \mathrm{q} 2$. Ann Genet Paris 1985;28:58-60.

10 Turleau C, de Grouchy J, Chavin-Colin F, Roubin M. Trisomie 15q distale. Ann Genet 1977;20:214-16.

11 Zabel B, Baumann W. Trisomie partielle pour la partie distale du bras long de chromosome 15 par translocation X/15 maternelle. Ann Genet 1977;20: 285-9.

12 Gregoire MJ, Boue J, Junien C, Pernot C, Gilgenkrantz S, Zergollern L. Duplication $15 \mathrm{q} 22 \rightarrow 15 \mathrm{qter}$ and its phenotypic expression. Hum Genet 1981:59:429-33.

13 Goldstein DJ, Ward RE, Nichols WC, Palmer CG. Familial t $(8 ; 15)(\mathrm{p} 23.3$; q22.3): report of two cases with $\operatorname{dup}(15)(\mathrm{q} 22.3 \rightarrow \mathrm{qter}) . \mathcal{F}$ Med Genet 1987; 24:684-7.

14 Schnatterly P, Bono KL, Robinow M, Wyandt HE, Kardon N, Kelly TE. Distal 15q trisomy: phenotypic comparison of nine cases in an extended family. Am f Hum Genet 1984;36:444-51.

15 Herr HM, Scott CI Jr, Horton SJ. De novo interstitial direct duplication of 15q: 46,XY,dir dup(15) (pter $\rightarrow$ q224::q14 $\rightarrow$ q21.1::q24 $\rightarrow$ qter). F Med Genet 1983;20:473-5

16 Howard-Peebles PN, Scarbrough PR, Sharpe J, Finley WH, Finley SC. A complex chromosome rearrangement resulting in trisomy $15 \mathrm{q} 22 \rightarrow$ qter. $\mathcal{F}$ Med Genet 1982;19:224-7. 


\section{BOOK REVIEW}

If you wish to order or require further information regarding the titles reviewed here, please write to or telephone the BMJ Bookshop, PO Box 295, London WC1H 9JR. Tel 0207383 6244. Fax 0207383 6662. Payment can be made by cheque in sterling drawn on a UK bank or by credit card (Mastercard, Visa, or American Express) stating card number, expiry date, and full name. (The price and availability are occasionally subject to revision by the Publishers.)

An atlas of preimplantation genetic diagnosis. Yury Verlinsky, Anver Kuliev. New York: The Pathenon Publishing Group, 2000.

Preimplantation genetic diagnosis (PGD) was first carried out at the Hammersmith Hospital in London by Robert Winston and Alan Handyside, who developed a way of determining the sex of the human embryo before implantation, thereby reducing the risk of $\mathrm{X}$ linked disease. PGD is yet another example of a technological advance that originated in the UK but because of lack of resources and investment has been extensively taken up and developed elsewhere in Europe and particularly in the USA. As the authors of this Atlas state, in the ensuing 10 years, as many as 40 PGD centres have been established, in 17 countries; to date these centres have performed approximately 2000 clinical IVF cycles for PGD resulting in nearly 500 pregnancies. More than two thirds of these cycles were performed in the USA; the largest number (almost 1000) was contributed by the Reproductive Genetics Institute, Chicago, to which the authors belong.

The Atlas is technically detailed and beautifully illustrated. It consists of two sections; the first is entitled "A Review of Methods and Experience in PGD", the second is "PGD Illustrated". The written text is brief, consisting of 50 pages, but as befits an atlas the second section extends over 100 pages. The early part covers normal and abnormal preimplantation development, from oocyte maturation onwards. This part is particularly revealing and useful for the reader with a genetic rather than an embryological background. Next is the chapter on micromanipulation and biopsy of polar bodies and single blastomeres from cleavage stage embryos. Step by step instructions are given for making the necessary tools for polar body removal, although only one other centre besides their own uses polar bodies for PGD. Similarly, the following chapter on nuclear transfer techniques for visualisation of chromosomes in polar bodies and blastomeres describes esoteric technology that is not carried out in any other centre and is of limited clinical use, although it has many research applications. There follow the two chapters that cover the Chicago group's approaches to chromosome analysis by FISH and single cell DNA analysis for the detection of dominant and recessive disorders.

The atlas is described as "An illustrated textbook and reference for clinicians". It will best fulfil that role, since it is of limited use to either the embryologist or geneticist already working in the growing field of PGD. It will enable the clinician to understand better the complexity of the task facing the laboratory professionals when a patient is referred for genetic diagnosis before the embryo implants.

JOY DELHANTY

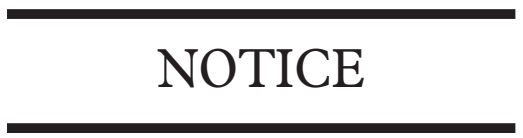

\section{British Human Genetics Conference}

The British Human Genetics Conference will be held at the University of York, England, on 10-12 September 2001. There will be sessions on: Quality in the process of genetic counselling; Functional significance of SNP's role in common disease and pharmacogenetics; Audit in genetics; Chromosome structure and function; $\mathrm{Rb}$ molecular and cellular biology; Eye genetics; Complex disorders; Neurodegeneration; and The Carter Lecture by Professor Nick Hastie.

\section{CORRECTION}

In the August 2000 issue of the journal, in the electronic letter $e 10$ "Duplication of medial 15 q confirmed by FISH" by Browne et al, the name of one of the authors, A Protopapas, was regrettably misspelt.

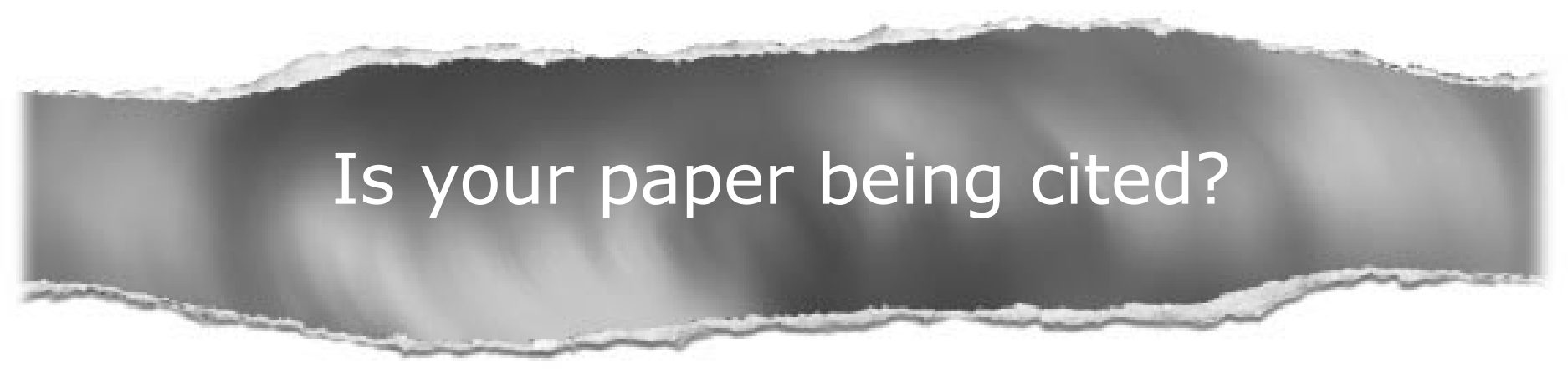

\section{CiteTrack service}

CiteTrack will alert you by email whenever new content in the Journal of Medical Genetics or a participating journal is published that matches criteria you want to track

Topics: Tell CiteTrack which words or subjects to watch for in new content Authors: Be alerted whenever key authors you are following publish a new paper Articles: Know whenever a paper of interest to you is referenced by another paper

\section{www.jmedgenet.com}

